\title{
Aplicabilidade clínica das células-tronco mesenquimais indiferenciadas do tecido adiposo para cirurgias de regeneração óssea de maxila e mandíbula atrófica
}

\author{
Clinical applicability of undifferentiated mesenchymal stem cells from adipose tissue for bone \\ regeneration surgeries of the atrophic maxilla and mandible \\ Aplicabilidad clínica de células madre mesenquimales indiferenciadas del tejido adiposo para \\ cirurgías de regeneración ósea de maxilar y mandibula atrofica
}

Recebido: 08/05/2021 | Revisado: 16/05/2021 | Aceito: 21/05/2021 | Publicado: 07/06/2021

\author{
Ísis de Fátima Balderrama \\ ORCID: https://orcid.org/0000-0002-8606-9054 \\ Universidade Estadual Paulista, Brasil \\ E-mail: if.balderrama@unesp.br \\ Rafael Ferreira \\ ORCID: https://orcid.org/0000-0001-5879-2782 \\ Universidade Federal do Mato Grosso do Sul, Brasil \\ E-mail: rafael_ferreira@ufms.br \\ Moira Pedroso Leão \\ ORCID: https://orcid.org/0000-0003-3724-911X \\ Curityba Biotech, Centro de Processamento Celular, Brasil \\ E-mail: moirapedroso@gmail.com \\ Elcio Marcantonio-Júnior \\ ORCID: https://orcid.org/0000-0003-1294-2305 \\ Universidade Estadual Paulista, Brasil \\ E-mail: elcio.marcantonio@unesp.br
}

\begin{abstract}
Resumo
Objetivo: Esta revisão de literatura tem como objetivo realizar uma busca estratégica de artigos científicos sobre a aplicabilidade das células-tronco do tecido adiposo associado aos enxertos em cirurgias de regeneração óssea em maxila e mandíbula atrófica. Metodologia: Foi realizada uma estratégia de busca em quatro bases de dados (PubMed, Embase, Web of Science e Cochrane Library) por meio do cruzamento de diferentes descritores de acordo com a estratégia PICO. Resultados: Foram recuperados 206 artigos, porém, de acordo com os critérios de inclusão e exclusão desta revisão, um total de 9 artigos foram selecionados para uma análise crítica e analítica. Os resultados dos artigos desta revisão demonstraram que para a obtenção das células-tronco mesenquimais (CTMs) do tecido adiposo, pode ser coletada através do tecido abdominal (TA) ou pela bola de Bichat (BB). Estudos que realizaram a caracterização das células presentes no tecido adiposo, resultam em expressão de marcadores de células mesenquimais. Para a transplantação em abordagem clínica, as cirurgias de levantamento de seio maxilar, regeneração óssea em pré-maxila e mandíbula atrófica, assim como fratura de côndilo, demonstraram bons resultados quando as CTMs ou com a fração vascular estromal (FVE) foram associados com enxerto autógeno, xenógeno ou aloplástico. Conclusão: Apesar da limitada evidência científica, a abordagem celular com FVE e as CTMs derivadas do TA ou BB demonstram ser seguras e eficazes quando associadas com enxerto autógeno, sintético, alógeno ou xenógeno, favorecendo o potencial osteogênico nas cirurgias de regeneração óssea.
\end{abstract}

Palavras-chave: Regeneração óssea; Engenharia tecidual; Células-tronco.

\begin{abstract}
Objectives: This literature review aimed to perform a strategic search for scientific articles on the applicability of adipose tissue stem cells associated with grafts in bone regeneration surgeries in the maxilla and atrophic mandible. Methodology: A search strategy was carried out in four databases (PubMed, Embase, Web of Science and Cochrane Library) by crossing different descriptors according to the PICO strategy. Results: 206 articles were obtained, however according to the inclusion and exclusion criteria of this review, a total of 9 articles were selected for a critical and analytical analysis. The results of articles from this review showed that for obtaining mesenchymal stem cells (MSCs) from adipose tissue, it can be collected from abdominal tissue (TA) or by buccal fat pad (BB). Studies that carried out the characterization of the cells present in the adipose tissue result in expression of markers of mesenchymal cells. For transplantation in a clinical approach, surgeries for maxillary sinus grafting, bone regeneration for atrophic premaxilla and mandible, as well as condyle fracture, demonstrated good outcomes when MSCs or the stromal vascular fraction (SVF) were associated with autogenous, alloplastic, allogenic or xenogenic grafts. Conclusion: According to the limited scientific evidence, the cellular approach
\end{abstract}


with SVF and CTMs derived from TA or BB prove to be safe and effective when associated with autogenous, alloplastic, allogenic or xenogenic grafts, improving the osteogenic potential in bone regeneration surgeries.

Keywords: Bone regeneration; Tissue engineering; Stem cells.

\section{Resumen}

Objetivo: Esta revisión de la literatura tiene como objetivo realizar una búsqueda estratégica de artículos científicos sobre la aplicabilidad de las células madre del tejido adiposo asociadas a los injertos en cirugías de regeneración ósea en el maxilar y la mandíbula atrófica. Metodología: Se realizó una estrategia de búsqueda en cuatro bases de datos (PubMed, Embase, Web of Science y Cochrane Library) cruzando diferentes descriptores según la estrategia PICO. Resultados: 206 artículos fueron recuperados, más de acuerdo con los criterios de inclusión y exclusión de esta revisión, un total de 9 artículos fueron seleccionados para su análisis crítico y analítico. Los resultados mostraron que para obtener células madre mesenquimales (MSC) a partir del tejido adiposo, se pueden recolectar del tejido abdominal (TA) o mediante la bola de Bichat (BB). Los estudios que llevaron a cabo la caracterización de células presentes en el tejido adiposo, dan como resultado la expresión de marcadores de células mesenquimales. Para el trasplante en un abordaje clínico, las cirugías para el levantamiento del seno maxilar, la regeneración ósea en la atrófica premaxila y mandíbula, así como la fractura del cóndilo, mostraron buenos resultados cuando las CMM o la fracción estromal vascular (FVE) cuando asociada con injerto autógenos, aloplástico, alogénicos y xenogénicos. Conclusión: De acuerdo con la limitada evidencia científica, el abordaje celular con FVE y CTMs derivados de TA o BB resulta en un seguro y efectivo método cuando se asocia a injertos autógenos, aloplástico, alogénicos y xenogénicos, favoreciendo el potencial osteogénico en cirugías de regeneración ósea.

Palabras clave: Regeneración ósea; Ingeniería de tejidos; Células madre.

\section{Introdução}

A remodelação óssea do rebordo alveolar devido à perda dentária demonstra uma relação com deficiência óssea em dimensões horizontais e verticais que, por sua vez, uma abordagem cirúrgica nestes casos com aumento ósseo pode ser preconizada a partir diversos protocolos e enxertias (Nkenke, Neukam 2014; Chiapasco et al., 2018).

O enxerto autógeno é descrito como padrão ouro por demonstrar propriedades de osteogênese, assim como presença de células osteocompetentes e fatores de crescimento com alta capacidade de formar novo osso (Yamada, Egusa 2018; Marx 1994; Cornell 1998; Garg 2004). Uma das desvantagens da técnica do enxerto autógeno é a necessidade de uma área doadora do mesmo indivíduo o que acomete uma morbidade assim como, complicações no pós-operatório (Garg 2004; Neo et al., 2000; Marx, Garg 2005; Nkenke, Neukam 2014), reabsorção do enxerto ósseo e possíveis influências na taxa de sucesso dos implantes dependendo do tipo do implante instalado (Nkenke, Neukam 2014). Como alternativa ao osso autógeno, são descritas o uso de biomateriais, que demonstram alcançar uma remodelação óssea ideal para a regeneração óssea (Haugen et al., 2019; Schmitt et al., 2013; Pelegrine et al., 2011), por apresentarem propriedades osteocondutoras e fatores osteoindutores, com vantagem de suportar e promover o crescimento de nova formação óssea (Imam et al., 2017).

A literatura investiga sobre a aplicabilidade das células-tronco em associação com os biomateriais (Shang et al., 2021), ou seja, a engenharia tecidual. Devido o osso autógeno possuir células progenitoras, osteoblastos e células-tronco (Nkenke \& Neukam 2014), uma possível associação destas células ou fatores de crescimento a um biomaterial osteocondutor poderia resultar em um biomaterial potencialmente osteogênico comparável ao osso autógeno (Froum et al., 2013; Pelegrine et al., 2011; Khojasteh et al. 2017; Khojasteh et al. 2019; Hernigou et al., 2014).

A aplicação das células-tronco derivadas da medula óssea ou do tecido adiposo é relatada por diversos estudos clínicos na área da regeneração óssea craniofacial em humanos (Khojasteh et al. 2017; Akhlaghi et al. 2019; Khojasteh et al. 2019; Sauerbier et al, 2010; Pelegrine et al., 2016). Associar essas células aos biomateriais osteocondutores demonstra uma possibilidade devido à união das células e fatores de crescimento quando associada a um arcabouço a fim de potencializar a osteogênese e osteoindução para a formação óssea (Aloise et al., 2015; Pelegrine et al., 2014; Shang et al., 2021) ou seja, otimizando as características desse enxerto. 
O tecido adiposo demonstra ser uma fonte tecidual abundante de células autógenas para enxertia em casos de regeneração tecidual óssea associada com biomateriais (Zhu et al., 2008; Khojasteh et al., 2019; Zannettino et al., 2008). As células-tronco derivadas do tecido adiposo possuem uma capacidade de diferenciação em diversas linhagens celulares, sendo estas, células osteogênicas, adipogênicas, condrogênicas e miogênicas, e por demonstrarem características de auto-renovação, aderência plástica, diferenciação e expressão de marcadores mesenquimais $\left(\mathrm{CD} 34^{+}, \mathrm{CD} 44^{+}\right)$(Khojasteh et al., 2019; Khojasteh \& Sadeghi 2016).

Esta revisão de literatura teve como objetivo elencar as evidências da aplicabilidade clínica das células-tronco mesenquimais derivadas do tecido adiposo humano (TA e BB) a fim de aprimorar as cirurgias de regeneração óssea em regiões de atrofia na maxila e mandíbula.

\section{Metodologia}

Questão foco

A pergunta foco utilizada nesta revisão narrativa foi: "Qual a evidência científica clínica sobre o uso das célulastronco mesenquimais indiferenciadas e fração vascular estromal do tecido adiposo associado à enxertia autógena, xenógena e aloplástica para regeneração óssea?".

\section{Estratégia de busca}

Para a busca de artigos foram utilizadas as bases de dados PubMed, Embase, Web of Science e Cochrane Library, sendo as estratégias de busca adotadas de acordo com a estratégia PICO com auxílio do "AND" e "OR" entre as palavraschaves e os "mesh terms", tais como: População ("sinus floor augmentation"; "alveolar ridge augumentation"; "bone regeneration"; "alveolar bone atrophy"; "alveolar bone loss"); Intervenção ("adult stem cells"; "adipose tissue"; "mesenchymal stem cells"; "tissue engineering"; "regenerative medicine"; "mesenchymal stromal cells"; "abdominal adipose tissue"); Desfecho ("bone grafting"; "biomaterials"; "autogenous bone"); Resultado ("biopsies"; "bone formation"; "comparative histology"; "computed tomography scanner $x$ ray").

Como critérios de inclusão foram selecionados somente artigos que possuíssem metodologia de estudos clínicos randomizados, estudos clínicos piloto, série de casos, ou relatos de casos clínicos; assim como, estudos que abordassem a terapia tecidual com as células-tronco mesenquimais derivadas do tecido adiposo. Os critérios de exclusão foram artigos de revisões de literatura, revisões sistemáticas, estudos em animais, estudo in vitro, e estudos que não abordassem a temática selecionada ou em outro idioma que não fosse inglês, português ou espanhol.

Por se tratar de uma revisão analítica da literatura, não foram adotadas escala para análise das qualidades dos artigos, bem como avaliação dos riscos de viés. A inserção de artigos envolvendo séries ou relatos de casos faz-se necessário para englobar o maior número de estudos correspondentes ao tema. Como metodologia para análise estatística dos artigos, foi realizada uma abordagem qualitativa dos estudos.

\section{Resultados}

Após análise da base da busca realizada, chegou-se ao total de nove artigos (Kulakov et al. 2008; Prins et al. 2016; Khojasteh \& Sadeghi et al. 2016; Khojasteh et al. 2017; Castilho-Cardiel et al. 2017; Farré-Guasch et al. 2018; Solakoglu et al. 2019; Akhlaghi et al. 2019; Khojasteh et al. 2019) para essa revisão crítica e analítica. A figura 1 demonstra detalhadamente o fluxograma do processo de seleção dos artigos encontrados. 
Figura 1. Fluxograma do processo de seleção dos artigos.
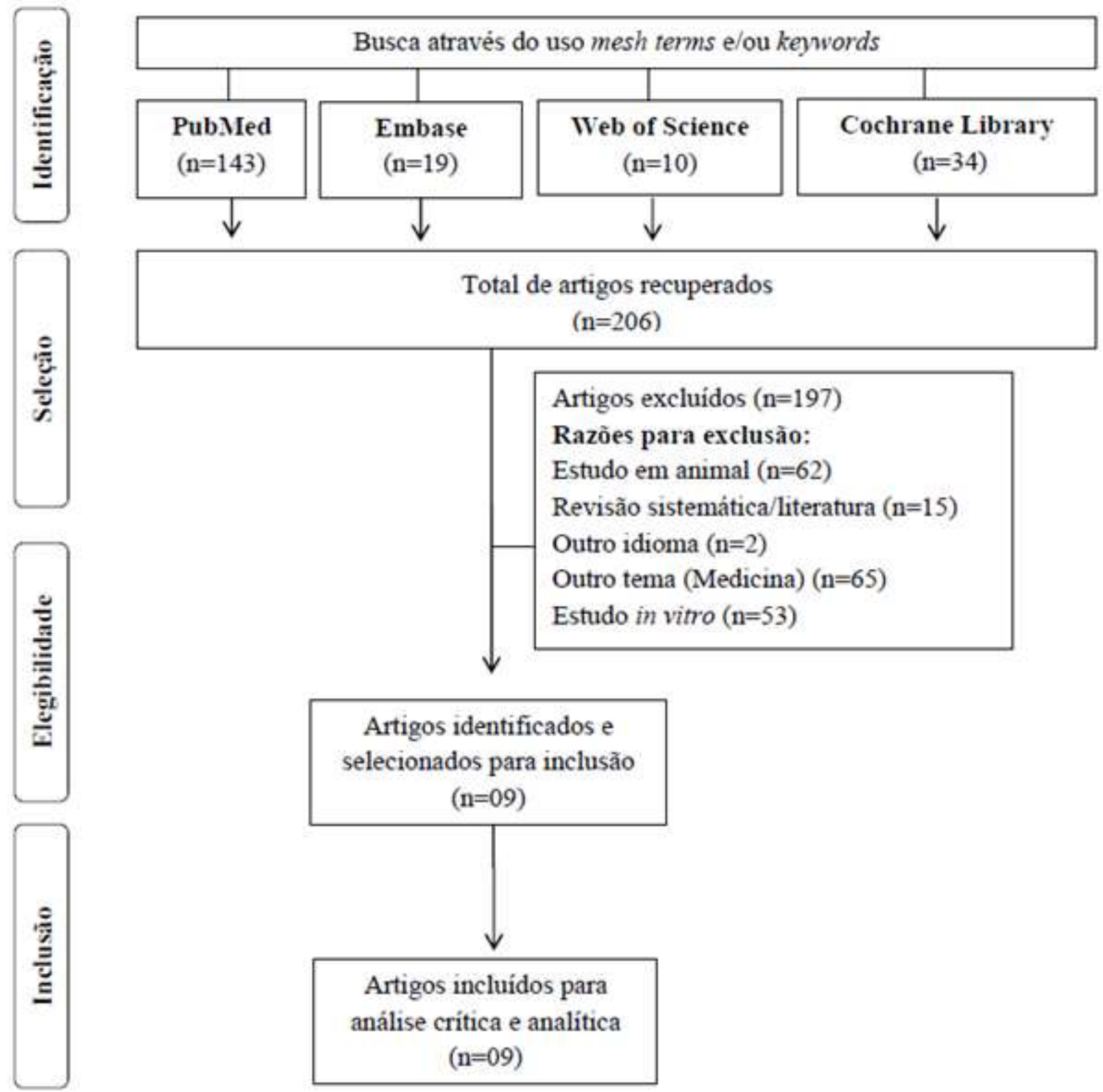

Fonte: Autores.

Na Tabela 1, estão presentes, de forma resumida, os 09 artigos clínicos que abordam o uso da CTM-TA ou FVE em cirurgias de maxila e mandíbula atrófica. Já na tabela 2, estão apresentadas as formas de utilização dos produtos utilizados nas cirurgias de regeneração. 
Tabela 1. Apresentação dos dados resumidos.

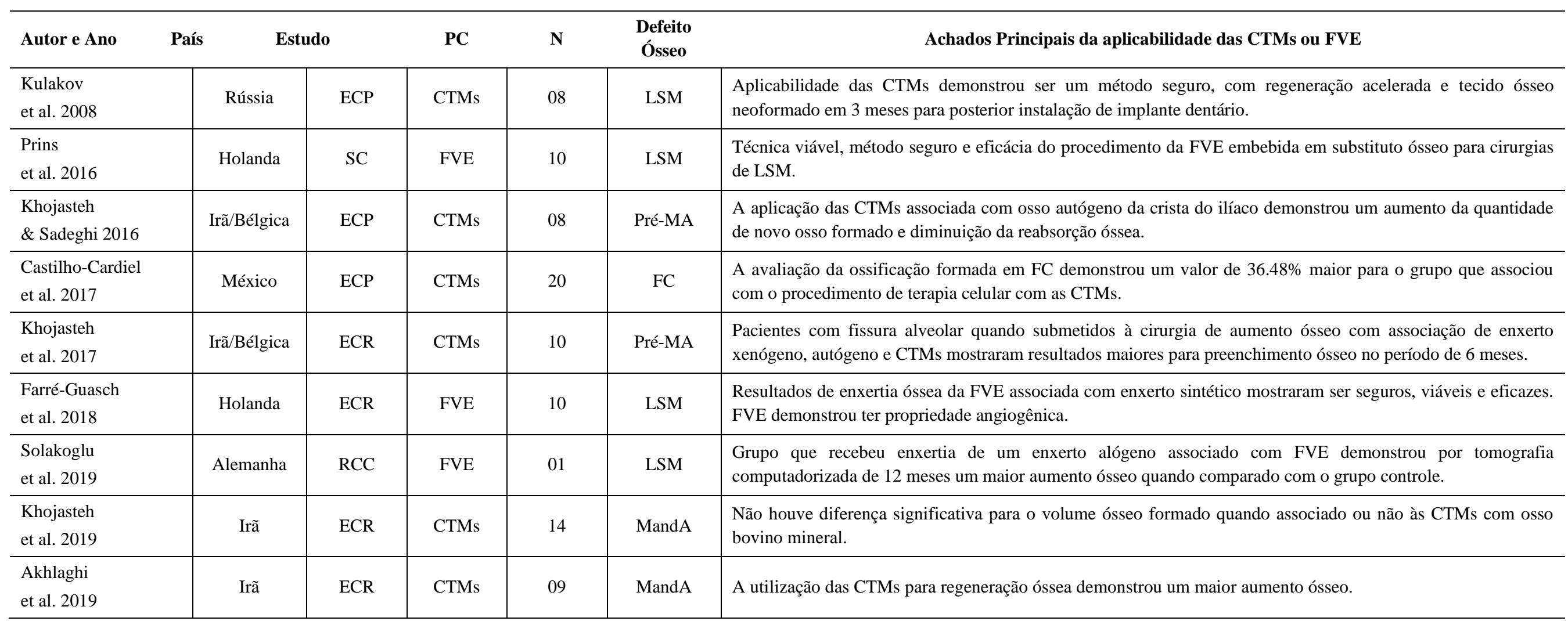

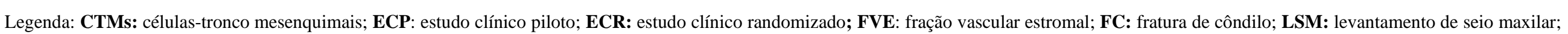
MandA: mandíbula atrófica; N: número de indivíduos no estudo; PC: processamento celular; Pré-MA: pré-maxila atrófica; RCC: relato de caso clínico; SC: série de casos.

Fonte: Autores. 
Research, Society and Development, v. 10, n. 6, e48810616023, 2021

(CC BY 4.0) | ISSN 2525-3409 | DOI: http://dx.doi.org/10.33448/rsd-v10i6.15900

Tabela 2. Apresentação dos protocolos e materiais utilizados nos artigos selecionados.

\begin{tabular}{|c|c|c|c|c|c|}
\hline \multirow[t]{2}{*}{ Autor e Ano } & \multicolumn{3}{|c|}{ Aplicabilidade Clínica do Tecido Adiposo } & \multicolumn{2}{|c|}{ Re-intervenção } \\
\hline & Coleta & Transplantação & Aplicação CTM-TA + Biomaterial & Biópsia & Tomografia \\
\hline $\begin{array}{l}\text { Kulakov } \\
\text { et al. } 2008\end{array}$ & $\begin{array}{l}\text { RO:Abd } \\
\text { QT: NR }\end{array}$ & $\begin{array}{l}21 \text { dias } \\
\text { após a coleta do tecido }\end{array}$ & $\begin{array}{l}\text { GT: EX (BioOss®) + CTMs } \\
\text { GC: EX }\end{array}$ & $3 \mathrm{M}$ & 1,3 e $6 \mathrm{M}$ \\
\hline $\begin{array}{l}\text { Prins } \\
\text { et al. } 2016\end{array}$ & $\begin{array}{l}\text { RO: Abd } \\
\text { QT:150 mL }\end{array}$ & Mesmo estágio cirúrgico & $\begin{array}{l}\text { GT: ES (Beta-tricálcio fosfato) + FVE } \\
\text { GC: ES }\end{array}$ & $6 \mathrm{M}$ & $6 \mathrm{M}$ \\
\hline $\begin{array}{l}\text { Khojasteh \& } \\
\text { Sadeghi } 2016\end{array}$ & $\begin{array}{l}\text { RO:BB } \\
\text { QT: } 3-5 \mathrm{~mL}\end{array}$ & $\begin{array}{c}\text { 14-21 dias } \\
\text { após a coleta }\end{array}$ & $\begin{array}{l}\left.\text { GT: EA (crista do ilíaco) + EAl (SureOss }{ }^{\circledR}\right)+ \text { CTMs } \\
\text { GC: EA + EAl }\end{array}$ & $5 \mathrm{M}$ & $5 \mathrm{M}$ \\
\hline $\begin{array}{l}\text { Castilho-Cardiel } \\
\text { et al. } 2017\end{array}$ & $\begin{array}{l}\text { RO:Abd } \\
\text { QT: NR }\end{array}$ & $\begin{array}{c}24 \text { horas } \\
\text { após a coleta do tecido }\end{array}$ & $\begin{array}{l}\text { GT: Redução da fratura + CTMs } \\
\text { GC: Redução da fratura }\end{array}$ & NSA & 4 e $12 \mathrm{~S}$ \\
\hline $\begin{array}{l}\text { Khojasteh } \\
\text { et al. } 2017\end{array}$ & $\begin{array}{l}\text { RO:BB } \\
\text { QT: } 3-5 \mathrm{~mL}\end{array}$ & $\begin{array}{l}14 \text { dias } \\
\text { após a coleta do tecido }\end{array}$ & $\begin{array}{l}\text { GT: EA (ramo da mandíbula) + CTMs + EX (Cerabone®) } \\
\text { GT: EA (crista do ilíaco) + CTMs+ EX (Cerabone®) } \\
\text { GC: EA (crista do ilíaco) }\end{array}$ & $6 \mathrm{M}$ & $6 \mathrm{M}$ \\
\hline $\begin{array}{l}\text { Farré-Guasch } \\
\text { et al. } 2018\end{array}$ & $\begin{array}{l}\text { RO:Abd } \\
\text { QT: } 125 \mathrm{~mL}\end{array}$ & Mesmo estágio cirúrgico & $\begin{array}{l}\text { GT: ES (Beta-tricálcio fosfato) + FVE } \\
\text { GC: ES }\end{array}$ & $6 \mathrm{M}$ & NSA \\
\hline $\begin{array}{l}\text { Solakoglu } \\
\text { et al. } 2019\end{array}$ & $\begin{array}{l}\text { RO:Abd } \\
\text { QT: } 150 \mathrm{~mL}\end{array}$ & Mesmo estágio cirúrgico & GU: EAl (Zimmer®) + FVE & $6 \mathrm{M}$ & $34 \mathrm{~S}$ \\
\hline $\begin{array}{l}\text { Khojasteh } \\
\text { et al. } 2019\end{array}$ & $\begin{array}{l}\text { RO:BB } \\
\text { QT: } 3-5 \mathrm{~mL}\end{array}$ & $\begin{array}{l}\text { 7-14 dias } \\
\text { após a coleta do tecido }\end{array}$ & $\begin{array}{l}\text { GT:EX (osso bovino mineral) + CTMs } \\
\text { GC:EX (osso bovino mineral) + EA (ramo da mandíbula) }\end{array}$ & NSA & $6 \mathrm{M}$ \\
\hline $\begin{array}{l}\text { Akhlaghi } \\
\text { et al. } 2019\end{array}$ & $\begin{array}{l}\text { RO:BB } \\
\text { QT: 3-5mL }\end{array}$ & $\begin{array}{l}14 \text { dias } \\
\text { após a coleta do tecido }\end{array}$ & $\begin{array}{l}\text { GT:EA (crista do ilíaco) + Membrana amniótica + CTMs } \\
\text { GC:EA + Membrana amniótica }\end{array}$ & NSA & $5 \mathrm{M}$ \\
\hline
\end{tabular}

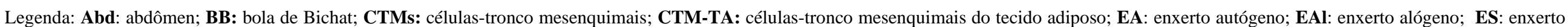

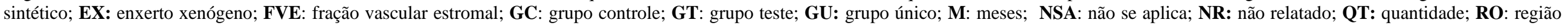
obtida; S: semanas.

Fonte: Autores. 


\section{Processamento celular do tecido adiposo do tecido abdominal}

Os autores Kukalov e colaboradores (2008) coletaram do tecido abdominal da área anterior por lipoaspiração, o material foi levado ao laboratório em um recipiente dentro de 1 hora. O tecido foi lavado com solução Versen (PanEko®) e tripsina 1:1 (PanEko®) e incubado por 2-3 horas a $37^{\circ} \mathrm{C}$. As células foram isoladas, centrifugadas e transferidas para meio de cultura NUNC e DMEM/F12 (PanEko®). O tecido adiposo contendo células mesenquimais foi cultivado após 1.5 e 2 semanas, e as células foram trocadas de meio entre 5 a 7 vezes antes da terceira passagem. Após isso, a imunofenotipagem por citometria de fluxo foi realizada, e aos 7 dias uma troca do meio para meio osteogênico para diferenciação celular. No momento do procedimento da transplantação, os blocos de enxertia foram lavados com solução de Hanks (PanEko®) contendo cefazolin e uma solução de trombina foi adicionada até a polimerização, sendo assim, o biomaterial BioOss® foi associado com o material osteogênico (CTMs) previamente preparado.

De forma semelhante, Prins e colaboradores (2016), utilizaram um total de $150 \mathrm{~mL}$ de tecido adiposo derivado da lipoaspiração do abdômen para o processamento celular. As seringas contendo o tecido adiposo e o fluido da liposucção foi então transferido para uma centrífuga de isolamento de células-tronco (800/CRS aparelho USA) resultando em uma quantidade final de $5 \mathrm{~mL}$ em suspensão celular. A viabilidade celular (>70\%) foi realizada (Nucleocounter NC100) para analisar a presença de células mortas e vivas, e para a transplantação, um total de $7.5 \times 10^{6}$ células por mL foram embebidas em $100 \%$ de partículas do biomaterial derivado de ß-tricálcio fosfato (Ceros®) ou com o Bone Ceramic da Straumann®. Um total de $2 \times 10^{6}$ células com adicionado com dois gramas de biomaterial, e as células foram incubados por 30 minutos em temperatura ambiente, após lavagem de 5 minutos com uma solução de Ringers (Lactate®), e assim o biomaterial foi enxertado em áreas da cirurgia.

Solakoglu e autores (2019) realizaram a técnica da coleta do tecido adiposo pela lipoaspiração, um total de $100 \mathrm{~mL}$ de tecido adiposo foi aspirado e as células foram isoladas pelo aparelho (InGeneron-Transpose RT system®). O tempo total de processamento em temperatura de $39^{\circ}$ foi de 70 minutos. Para a transplantação, um total de 7 gramas de partículas de enxerto alógeno (Zimmer®) foi reidratado com $1.5 \mathrm{~mL}$ de sangue com as células derivadas do tecido adiposo $\left(5 \times 10^{6} \mathrm{células} \mathrm{em} 3 \mathrm{~mL}\right.$ de solução salina) por 30 minutos e assim o biomaterial com as células foram enxertadas.

Farré-Guasch e colaboradores (2018) utilizaram o tecido adiposo da lipoaspiração, sendo um total de $125 \mathrm{~mL}$ de tecido adiposo coletado por lipoaspiração. As células foram então transportadas para um laboratório especial e então processadas por um aparelho (CE marked Celution device, Cytori Therapeutics®) para obtenção da FVE. Para a transplantação foi analisado in vitro a viabilidade e número celular de acordo com uma porcentagem maior que 70. Para implantação das células no biomaterial, uma concentração celular de $10^{7}$ células foi armazenada com o biomaterial e a cada 2 x $10^{5}$ células em 1 grama do biomaterial.

Castilho-Cardiel e colaboradores (2017) utilizaram o tecido adiposo da lipoaspiração, sendo que o tecido adiposo foi coletado 24 horas antes da transplantação, e as células foram enviadas ao laboratório. As amostras foram incubadas e após apresentarem 37\% de células aderidas na placa, foi realizada a separação. Aproximadamente 400 mil células foram obtidas (não adiposas). Então o tecido adiposo contendo $1 \times 10^{7}$ de células até 6 × $10^{7}$ com mais de $90 \%$ de viabilidade foi estimado para a transplantação. As células foram utilizadas para aplicação em fratura do côndilo, e após isso uma placa de titânio foi instalada e posicionada no ato cirúrgico.

\section{Processamento celular do tecido adiposo da Bola de Bichat}

Segundo o estudo de Khojasteh \& Sadeghi e autores (2016), a metodologia preconizada determinou uma coleta de uma quantidade variante entre 3-5 mL de tecido da BB e imediatamente inserido ao meio DMEM. Em ambiente de fluxo laminar de laboratório foi realizada uma lavagem com PBS por 30 minutos e o meio foi trocado semanalmente após a fase de 
confluência das células. As células foram transplantadas após a terceira e quarta passagem celular, e um total de $6 \times 10^{4}$ células foi preparado para as análises, adicionalmente um total de $20 \mathrm{~mL}$ do sangue do paciente foi coletado, centrifugado e armazenado em temperatura de $-20^{\circ} \mathrm{C}$ para procedimento laboratorial do processamento celular. Um arcabouço foi então formado, contendo $5 \mathrm{mg}$ do biomaterial posicionado dentro de uma placa de cultura de 96 poços, sendo assim, as células foram submersas no bimaterial com quantidade de $10^{5} \mathrm{em}$ meio osteogênico e o biomaterial foi mantido por 7 dias no laboratório até o procedimento cirúrgico de enxertia.

O estudo de Khojasteh e co-autores (2017), utilizou uma quantidade de 3-5 $\mathrm{mL}$ de tecido adiposo coletado e inserido no DMEM (mesma metodologia de Khojasteh \& Sadeghi 2016). Na transplantação, o sangue do indivíduo foi coletado $20 \mathrm{~mL}$ para o procedimento de manuseio das células, assim realizado a citometria do fluxo para determinar os marcadores de superfície de células mesenquimais e hematopoiéticas. Outro estudo do mesmo grupo de pesquisadores, Khojasteh e colaboradores (2019), coletaram 3-5 mL de tecido para o isolamento celular, o tecido foi digerido em DMEM contendo $1 \%$ colagenase tipo1 por 1 hora em uma estufa incubadora, sendo assim as células foram suspensas e transferidas para uma placa e as células foram cultivadas para preparação com o biomaterial e assim a transplantação cirúrgica. Por fim, o estudo Akhlaghi e co-autores (2019), utilizou a coleta de 3-5 mL de tecido e enviado para isolamento celular em laboratório, as células foram incubadas em meio DMEM, e acompanhadas até a terceira passagem. Foi coletado adicionalmente do paciente um total de 20 $\mathrm{mL}$ de sangue para o procedimento do processamento celular, assim como as células foram unidas com membranas congeladas derivadas de mães doadoras de membrana amnióticas.

\section{Caracterização e diferenciação das células do tecido adiposo}

O estudo de Prins e colaboradores (2016) analisaram as células provenientes da FVE e como resultados demonstrou porcentagem positiva de células com expressão de CD29 (78\%), marcador de adesão celular e marcador de célula mesenquimal CD90 (83\%), uma pequena população de célula mesenquimal CD105 (21\%) e CD73 (37\%), e alta porcentagem de 67\% para células hematopoiéticas (CD34), assim como para célula com característica endotelial-CD31 (47\%). Os dados celulares demonstraram uma média de porcentagem de viabilidade de $82.9 \%$ dentro da média de $253 \mathrm{~mL}$ de tecido adiposo coletado, com 47.4\% de célula viável. O estudo de Khojasteh \& Sadeghi (2016) analisaram as CTMs-BB onde demonstraram expressão positiva para os anticorpos mesenquimais CD44, CD90, CD73 e CD105 e negativo para CD45 e CD34, que são os marcadores hematopoiéticos. Assim como, os autores analisaram a diferenciação celular pelo teste de vermelho de Alizarina a fim de provar a multipotência das células isoladas, na terceira passagem já foi possível identificar as estruturas contendo nódulos mineralizados. Um mesmo grupo de pesquisadores investigaram as CTMs-BB, e como resultados, Khojasteh e colaboradores (2017) identificou que a análise feita por citometria de fluxo demonstrou que mais de 95\% de células foram detectadas positivas para CD70, CD93 CD44 e CD105; apenas CD 34 e CD 45 foram detectados como negativas. Assim como, os resultados da análise de vermelho de Alizarina demonstraram estruturas de nódulo mineralizados, ademais, a coloração avermelhada revelou resultados positivos para diferenciação adipogênica in vitro.

Khojasteh e colaboradores (2019), demonstraram resultados de citometria de fluxo onde identificaram que as CTMsBB possuíam um predomínio de células expressando marcadores de células mesenquimais em sua superfície (CD73 e CD105), assim como, adesão de células de CD44 e CD90. As células evidenciaram perfil negativo de marcadores hematopoiéticos de CD34 e CD45. Os resultados de vermelho de Alizarina demonstraram nódulos mineralizados e confirmação de capacidade osteogênica da cultura celular. Por análise de microscopia eletrônica de varredura, as células demonstraram morfologia em formato spindle e aderidas ao arcabouço do enxerto xenógeno bovino. 
Por fim, para o estudo de Akhlaghi e co-autores (2019), os resultados das análises celulares demonstraram fenótipo de células-tronco mesenquimais por meio da citometria de fluxo com expressão maior de 95\% das células para CD44, CD90, CD73 e CD105 enquanto negativa para CD45 e CD34 (marcadores hematopoiéticos). As células isoladas apresentaram morfologia de fibroblastos e após 14 dias de diferenciação osteogênica por análise de vermelho de Alizarina, as células obtiveram uma capacidade de diferenciação osteogênica in vitro.

\section{Análises histológicas ou histomorfométricas}

O estudo de Kulakov e autores (2008), analisaram as biópsias coletadas aos 3 meses após enxertia com a presença de CTMs-TA, e demonstrou que as amostras foram identificadas com tecido ósseo mineralizado maduro e presença de osteócitos. Prins et al., 2016, demonstrou através de cortes histomorfométricos que a associação do B-TCP + FVE obteve um valor aumentado (15.2\%) quando comparado com o grupo sem a FVE (13.3\%) no período de 6 meses, porém, sem diferença estatística.

Khojasteh \& Sadeghi (2016) analisaram as biópsias aos 5 meses de formação óssea das áreas enxertadas com osso autógeno da crista do ilíaco associado com osso alógeno sendo que um grupo teste teve a área embebida com CTMs e o grupo controle não. As imagens histológicas demonstraram que o grupo que recebeu as CTMs-BB possuíam uma maior densidade de osso trabecular, assim como osso normal com osteoblastos ativos produzindo matriz osteóide com presença de medula óssea, quando comparada com a imagem histológica do grupo controle. As medidas de osso neoformado foram de $65.32 \%$ e $49.21 \%$ para grupo teste e controle, respectivamente.

O estudo de Khojasteh e autores (2017) realizou biópsia aos 6 meses e demonstrou que quando o biomaterial é associado com as CTMs-BB, possui a presença de osso lamelar com osteoblastos sem infiltrado de células inflamatórias, demonstrando osso normal com osteoblastos ativos produzindo matriz osteóide. Do mesmo modo que o estudo de FarréGuasch et al., 2016, demonstrou que a FVE-TA em casos de regeneração óssea de levantamento de seio maxilar com enxerto aloplástico derivado do beta tricálcio fosfato demonstrou através de análise por biópsias aos 6 meses uma quantificação de número de vasos sanguíneos por análise histomorfométrica e imuno-histoquímica, evidenciando uma porcentagem de marcadores ósseos e potencial angiogênico para a regeneração tecidual para o grupo que utilizou FVE. Por fim, o estudo de Solakoglu e colaboradores (2019), realizou biópsia aos 6 meses após o levantamento de seio maxilar de um relato de caso, onde foi possível observar osteoblastos, adipócitos e osteóide nas lâminas histológicas, demonstrando a formação de osso neoformado.

\section{Análises radiográficas ou por tomografia computadorizada}

Os autores Prins e co-autores (2016) investigaram com enxerto aloplástico/beta-tricálcio fosfato associado com a FVE, e como resultados o tratamento demonstrou ser eficaz e seguro. As biópsias após 6 meses demonstraram porcentagem óssea e volume osteóide na formação óssea para o grupo com a FVE, assim como nas radiografias demonstrou resultados de beta-tricálcio fosfato $(10.2 \pm 1.5 \mathrm{~mm})$ e beta-tricálcio fosfato $+\mathrm{FVE}(9.9 \pm 1.3 \mathrm{~mm})$, assim como beta-cálcio fosfato $(12.4 \pm 1.6 \mathrm{~mm})$ e beta-cálcio fosfato +FVE $(12.1 \pm 1.6 \mathrm{~mm})$, porém os valores não mostraram diferença estatística. Porém a avaliação da microtomografia computadorizada demonstrou diferença estatística significante para o grupo beta-tricálcio fosfato $18.4 \%$ vs. $11.2 \%$ ou beta-cálcio fosfato $18.0 \%$ vs. $16.2 \%$ quando usado às células da FVE ou não, respectivamente. Pela análise histomorfométrica foi concluído que os maiores valores com formação óssea foram os grupos com a abordagem associada com a FVE.

No estudo de Khojasteh \& Sadeghi (2016), as CTMs-BB em casos de regeneração óssea de pré-maxila atrófica com enxerto autógeno em bloco da crista do ilíaco, sendo que foi associado no espaço entre os blocos enxerto alógeno particulado 
(SureOss®) associado ou não com as CTMs-TA, os autores demonstraram que o ganho de largura óssea por análise radiográfica de 5 meses $\left(3.94 \pm 1.62 \mathrm{~mm}^{2}\right)$ para o grupo de CTMs-TA + SureOss® (teste) quando comparado com o grupo controle $\left(3.01 \pm 0.89 \mathrm{~mm}^{2}\right)$ apenas o SureOss ${ }^{\circledR}$ (controle). Em adição, as biópsias coletadas aos 5 meses demonstraram resultados de nova formação óssea de $65.32 \%$ para o grupo teste quando comparado com o controle (49.21\%).

Já para o estudo de Khojasteh e co-autores (2017), os autores realizaram regeneração óssea em defeito ósseo da fissura alveolar, os resultados pela radiografia aos 6 meses demonstraram uma porcentagem maior de preenchimento ósseo para o grupo com as CTMs-TA associada com o enxerto xenógeno (Cerabone®) e autógeno da crista do ilíaco (82.5 $\pm 6.45 \%$ ) quando comparado com o grupo das CTMs-TA associado com Cerabone ${ }^{\circledR}$ e autógeno do ramo de mandíbula (75 $\left.\pm 3.5 \%\right)$ e seguido do grupo controle de apenas enxertia com o osso autógeno da crista do ilíaco (70 $\pm 10.40 \%)$. De forma semelhante, Solakoglu e colaboradores (2019) realizou um relato de caso clínico de levantamento de seio maxilar, e realizou imagem tomográfica previamente a cirurgia, após 34 semanas da regeneração óssea para instalação dos implantes, e após os 32 meses desde a primeira radiografia. Os resultados demonstraram que o grupo que recebeu a FVE-TA demonstrou um maior ganho ósseo quando comparado com o grupo que não recebeu a terapia.

Outro estudo de Kulakov e co-autores (2008), investigou a aplicabilidade das CTMs-TA em casos de regeneração óssea de levantamento de seio maxilar com enxerto xenógeno (BioOss®), e como resultados determinaram que o ganho ósseo pela tomografia computadorizada foi de $0.6 \mathrm{~cm}$ de comprimento para $2.5 \mathrm{~cm}$ após 3 meses da transplantação, demonstrando a formação óssea e a possibilidade de ancoragem dos implantes a serem instalados. Interessantemente, a aplicabilidade das CTMs-TA pode ser abordada com eficácia em casos de regeneração óssea de fratura de côndilo como foi utilizado por Castillo-Cardiel e colaboradores (2016), que demonstrou uma maior ossificação em 4 e 12 semanas para o grupo que recebeu as células-tronco, sendo que em 12 semanas uma taxa de ossificação de $36.48 \%$ foi evidenciada para o grupo teste (165.4 \pm 4.2) quando comparado com o controle $(112.9 \pm 2.0)$, dados avaliados por tomografia computadorizada. Quando as CTMs-BB em casos de regeneração óssea de mandíbula atrófica posterior com enxerto xenógeno apenas o estudo de Khojasteh e colaboradores (2019) analisou em comparação das CTMs-TA associada com osso bovino mineral anorgânico (teste) entre enxerto autógeno do ramo da mandíbula associado com osso bovino mineral inorgânico (controle), os resultados de ganho ósseo nos 6 primeiros meses por tomografia computadorizada demonstrou que o ganho na área vertical foi de $169.36 \pm 12.09$ $\mathrm{mm}^{2}$ (teste) vs. $164.91 \pm 3.74 \mathrm{~mm}^{2}$ (controle) e para o ganho na área horizontal foi $170.51 \pm 4.54 \mathrm{~mm}^{2}$ (teste) vs. $166.98 \pm 9.36$ $\mathrm{mm}^{2}$ (controle), porém, sem diferença estatística. Entretanto, vale reforçar que a proposta da técnica para obtenção das célulastronco derivadas do tecido adiposo é ser uma alternativa ao uso do autógeno, e sim associada com os biomateriais de origem sintética ou animal, e não a associação com o enxerto autógeno, sendo que a união de duas fontes autógenas pode evidenciar em maiores benefícios clínicos, porém levar maior morbidade ao paciente. Por outro lado, o estudo de Akhlaghi e colaboradores (2019) demonstraram em casos de regeneração de pré-maxila quando aplicado o osso autógeno da crista do ilíaco recoberto com uma membrana aminiótica (controle) e comparado com o osso autógeno da crista do ilíaco + membrana aminiótica + CTMs-BB (teste) e após 5 meses de acompanhamento pela análise da tomografia computadorizada foi demonstrado que valores de ganho ósseo foram significantemente maiores para o grupo com as CTMs-BB (4.42 $\pm 1.03 \mathrm{~mm})$ quando comparado com o grupo controle $(3.07 \pm 0.73 \mathrm{~mm})$.

\section{Sobrevivência dos implantes}

Apenas o estudo de Prins e co-autores (2016) realizaram um acompanhamento de 2.5 anos com enxerto sintético associado com FVE demonstrou que em apenas 1 implante instalado nessa área que foi evidenciado com uma boa estabilidade aos 3 meses, sendo que apenas 1 implante foi perdido devido dor, mobilidade e foi removido após 1 mês da enxertia. E o estudo de relato de caso de Solakoglu e co-autores (2019) demonstrou em um paciente que a FVE associada com o enxerto alógeno 
obteve um maior aumento ósseo por tomografia computadorizada em um acompanhamento final de com 12 meses, demonstrando sucesso dos implantes osseointegrados.

\section{Discussão}

Diante desta revisão de literatura, podemos determinar que a utilização das CTMs associado com biomateriais em áreas de maxila e mandíbula atrófica, demonstra ser um método viável e confiável. Porém, ainda faltam mais estudos clínicos randomizados para que assim haja padronização em alguns aspectos da técnica, isto é, estudos que avaliem as aplicações da coleta do tecido adiposo, em qual área são mais viáveis, qual protocolo padrão de centrifugação do tecido adiposo, assim como estudos in vitro para melhor análise de caracterização e diferenciação das células presentes na gordura e averiguar sua real potencialidade na regeneração óssea. Deve-se ponderar a aceitação pelo paciente ao procedimento de remoção do tecido gorduroso, bem como também os custos financeiros adicionais se são compatíveis com os benefícios clínicos adicionais. Vale salientar que o custo laboratorial para a obtenção das CTMs do tecido adiposo, para que possam ser considerados como requisitos para sua aplicabilidade clínica, o que pode ser uma limitação na rotina clínica, assim como a questão ética dependendo do país.

Os estudos de Kukalov e colaboradores (2008) e Castilho-Cardiel e colaboradores (2017) utilizaram o tecido adiposo coletado da gordura abdominal para processamento das CTMs, por outro lado, outros estudos tais como, Prins e autores (2016), Solakoglu e autores (2019), Farré-Guasch e colaboradores (2018) utilizaram a gordura abdominal para o processamento da FVE. Outra opção de fonte de tecido adiposo é a derivada da bola de bichat da mucosa jugal intra-oral, sendo que um total de quatro estudos utilizou essa metodologia, tais como, Khojasteh \& Sadeghi 2016, Khojasteh e colaboradores (2017), Khojasteh e colaboradores (2019) e Akhlaghi e colaboradores (2019), esses pesquisadores investigaram a aplicação das CTMs oriundas da BB, além do Akhlaghi e colaboradores (2019) que associou as CTMs da BB associada com outra fonte de CTMs, as membranas aminióticas de mães doadoras.

A obtenção do tecido adiposo possui algumas vantagens quando comparada com o aspirado de medula óssea, tais como, custo reduzido, a coleta operatória é menos invasiva e o potencial de células mesenquimais existentes são evidenciadas em maiores concentrações como descrito por Zhu e colaboradores (2008) e Zomorodian e colaboradores (2012). Para o processamento e a caracterização das células presentes no tecido adiposo, são utilizadas algumas categorias do tipo celular, como por exemplo, as células são manipuladas minimamente por meio da abordagem da FVE, ou então é manipulado através da expansão celular no laboratório, o que se pode ser obtido as CTMs-TA. Previamente a indicação do paciente para a coleta do tecido adiposo e assim a obtenção da FVE ou CTMs-TA, alguns exames complementares laboratoriais prévios a transplantação do material biológico são indicados, tais como, o exame laboratorial hematológico, de testes bioquímicos, clínicos e sorologia sanguínea para análise de HIV (Human Immunodeficiency Virus), HCV (Hepatitis C Virus) e HBV (Hepatitis B Virus) (Prins et al., 2016). O uso de exames provenientes a fim de identificar marcadores oncológicos, tais como, antígenos de carcinoembrionário Ca 19-9 para homens e Ca 15-3, Ca 19-9 para mulheres também podem ser realizados (Kulakov et al., 2008).

A aplicabilidade das CTMs derivadas do tecido adiposo em enxertos para aumento ósseo em cirurgias na Implantodontia demonstra um papel importante com resultados promissores (Khojasteh et al., 2019; Akhlaghi et al., 2019). A busca pelo avanço da tecnologia em melhores propriedades de enxertos xenógenos ou aloplásticos é constante, justamente a fim de substituir o enxerto autógeno, considerado o padrão-ouro devido à questão de morbidade pós-operatória (Imam et al., 2017). Os biomateriais de origem animal ou aloplástico possuem propriedades osteocondutores que promovem um crescimento de nova formação óssea (Imam et al., 2017), considerando que os enxertos autógenos possuem um subconjunto de células-tronco, 
células progenitoras e osteoblastos (Nkenke \& Neukam 2014), uma associação de células ou fatores de crescimento a um biomaterial osteocondutor pode resultar em um biomaterial potencialmente comparável ao enxerto padrão ouro, o autógeno (Khojasteh et al., 2019; Akhlaghi et al., 2019). Para isto, a associação das CTMs com biomateriais demonstra ser uma das indicações a fim de promover a capacidade em propriedades osteogênica (Kulakov et al., 2008; (Khojasteh et al., 2019; Akhlaghi et al., 2019). Os biomateriais após a associação com o as CTM ou FVE adquirem as propriedades semelhantes à enxertia com o osso autógeno. Diante disso, tal característica é de grande vantagem ao considerar as limitações em relação ao enxerto ósseo autógeno, como por exemplo, a disponibilidade de obtenção de outra área doadora e a morbidade pós-operatória do paciente, sendo assim a aplicabilidade do das CTM ou FVE associado aos biomateriais pode promover grandes benefícios na área da Implantodontia, sendo uma ferramenta importante na reconstrução de grandes áreas ou quando da limitação/ausência de material autógeno.

\section{Considerações Finais}

Portanto, frente às informações encontradas na literatura, é possível concluir que existem evidências que apresentam os benefícios da associação das CTM derivadas do tecido adiposo associada a enxertos autógenos, alógenos, xenógenos e aloplásticos em cirurgias de regeneração óssea em maxila e mandíbulas atróficas. Os estudos apontam o potencial benéfico na aceleração do processo de neoformação óssea, porém, mais estudos são necessários para se avaliar os protocolos, como também ampliar a sua aplicabilidade em outras cirurgias regenerativas.

\section{Referências}

Akhlaghi, F., Hesami, N., Rad, M. R., Nazeman, P., Fahimipour, F., Khojasteh, A. Improved bone regeneration through amniotic membrane loaded with buccal fat pad-derived MSCs as an adjuvant in maxillomandibular reconstruction. J Craniomaxillofac Surg. 2019 Aug;47(8):1266-1273.

Castillo-Cardiel, G., López-Echaury, A. C., Saucedo-Ortiz, J. A., Fuentes-Orozco, C., Michel-Espinoza, L. R., Irusteta-Jiménez, L., Salazar-Parra, M., González-Ojeda, A. Bone regeneration in mandibular fractures after the application of autologous mesenchymal stem cells, a randomized clinical trial. Dent Traumatol. 2017 Feb;33(1):38-44.

Chiapasco, M., Casentini, P. Horizontal bone-augmentation procedures in implant dentistry: prosthetically guided regeneration. Periodontol 2000.2018 Jun;77(1):213-240.

Cornell, C. N., Lane, J. M. Current understanding of osteoconduction in bone regeneration. Clin Orthop Rel Res, 1998 ; $355 \mathrm{~S}$ (Suppl): $267-73$.

Farré-Guasch, E., Bravenboer, N., Helder, M. N., Schulten, E. A. J. M., Ten, Bruggenkate, C. M., Klein-Nulend, J. Blood Vessel Formation and Bone Regeneration Potential of the Stromal Vascular Fraction Seeded on a Calcium Phosphate Scaffold in the Human Maxillary Sinus Floor Elevation Model. Materials (Basel). 2018 Jan 20;11(1):161.

Froum, S. J., Wallace, S., Cho, S. C., Rosenburg, E., Froum, S., Schoor, R. et al. A histomorphometric comparison of Bio-Oss alone versus Bio-Oss and platelet-derived growth factor for sinus augmentation: a postsurgical assessment. Int J Periodontics Restorative Dent. 2013; 33(3): 269-279.

Garg, A. K. Bone Biology, harvesting and grafting for dental implants. Chicago: Quintessence, 2004.

Haugen, H. J., Lyngstadaas, S. P., Rossi, F., Perale, G. Bone grafts: which is the ideal biomaterial? J Clin Periodontol, $2019 ; 46:$ (21): 92-102.

Hernigou, P., Desroches, A., Queinnec, S., Flouzat, Lachaniette, C. H., Poignard, A., Allain, J. Morbidity of graft harvesting versus bone marrow aspiration in cell regenerative therapy. Int Orthop. 2014; $38: 1855$.

Imam, M. A., Holton, J., Ernstbrunner, L., Pepke, W., Grubhofer, F., Narvani, A., Snow, M. A systematic review of the clinical applications and complications of bone marrow aspirate concentrate in management of bone defects and nonunions. Int Orthop, 2017; 41; 2213.

Khojasteh, A., Hosseinpour, S., Rezai, Rad, M., Alikhasi, M., Zadeh, H. H. Buccal fat pad-derived stem cells with anorganic bovine bone mineral scaffold for augmentation of atrophic posterior mandible: An exploratory prospective clinical study. Clin Implant Dent Relat Res. 2019 Apr;21(2):292-300.

Khojasteh, A., Kheiri, L., Behnia, H., Tehranchi, A., Nazeman, P., Nadjmi, N, Soleimani, M. Lateral Ramus Cortical Bone Plate in Alveolar Cleft Osteoplasty with Concomitant Use of Buccal Fat Pad Derived Cells and Autogenous Bone: Phase I Clinical Trial. Biomed Res Int. 2017;2017:6560234.

Khojasteh, A, Sadeghi N. Application of buccal fat pad-derived stem cells in combination with autogenous iliac bone graft in the treatment of maxillomandibular atrophy: a preliminary human study. Int J Oral Maxillofac Surg. 2016 Jul;45(7):864-71. 
Research, Society and Development, v. 10, n. 6, e48810616023, 2021

(CC BY 4.0) | ISSN 2525-3409 | DOI: http://dx.doi.org/10.33448/rsd-v10i6.15900

Kulakov, A. A., Goldshtein, D. V., Grigoryan, A. S., Rzhaninova, A. A., Alekseeva, I. S., Arutyunyan, I. V., Volkov, A. V. Clinical study of the efficiency of combined cell transplant on the basis of multipotent mesenchymal stromal adipose tissue cells in patients with pronounced deficit of the maxillary and mandibulary bone tissue. Bull Exp Biol Med. 2008 Oct;146(4):522-5.

Marx, R. E., Garg, A. K. Dental and craniofacial applications of platelet-rich plasma. Chicago: Quintessence, 2005.

Marx, R. E. Clinical application of bone biology to mandibular and maxillary reconstrution. Clin Plast Surg, 1994; 21:377-92.

Neo, M., Matsuhita, M., Morita, T. Pseudoaneurysm of the deep circumflex iliac artery: a rate complication of an anterior iliac bone graft donor site. Spine, 2000; $25: 1848-1851$

Nkenke, E., Neukam, F. W. Autogenous bone harvesting and grafting in advanced jaw resorption: morbidity, resorption and implant survival. Eur J Oral Implantol, 2014; 7 (2):S203-S217.

Oliveira, R. E. L., Hage, M., Carrel, J. P., Lombardi, T., Bernard, J. P. Rehabilitation of the edentulous posterior maxilla after sinus floor elevation using deproteinized bovine bone: a 9-year clinical study. Int J Implant Dent. 2012; 21(5):422-426.

Pelegrine, A. A., Aloise, A. C., Zimmermann, A., Oliveira, R. M., Ferreira, L. M. Repair of critical-size bone defects using bone marrow stromal cells: a histomorphometric study in rabbit calvaria. Part I: use of fresh bone marrow or bone marrow mononuclear fraction. Clin Oral Impl Res. 2014; 25: 567-572.

Pelegrine, A. A., Costa, C. E. S., Sendyk, W. R., Gromatzky, A. The comparative analysis of homologous fresh frozen bone and autogenous bone graft, associated or not with autogenous bone marrow, in rabbit calvaria: a clinical and histomorphometric study. Cell Tissue Bank. 2011; 12:171-184.

Pelegrine, A. A., Teixeira, M. L., Sperandio, M., Almada, T. S., Kahnberg, K. E., Pasquali, O. J., Aloise, A. C. Can bone marrow aspirate concentrate change the mineralization pattern of the anterior maxilla treated with xenografts? A preliminary study. Contemp Clin Dent 2016; 7(1): 21.

Pelegrine, A. A., Zimmermann, A., Oliveira, R. M., Ferreira, L. M. Repair of critical-size bone defects using bone marrow stem cells or autogenous bone with or without collagen membrane: a histomorphometric study in rabbit calvaria. Int J Oral Maxillofac Implants. 2015; 30(1): 208-15.

Prins, H. J., Schulten, E. A., Ten, Bruggenkate, C. M., Klein-Nulend, J., Helder, M. N. Bone Regeneration Using the Freshly Isolated Autologous Stromal Vascular Fraction of Adipose Tissue in Combination With Calcium Phosphate Ceramics. Stem Cells Transl Med. 2016 Oct;5(10):1362-1374.

Sauerbier, S., Stricker, A., Kuschnierz, J., Buhler, F., Oshima, T., Xavier, S. P., Schmelzeisen, R., Gutwald, R. Bone Marrow Concentrate and Bovine Bone Mineral for Sinus Floor Augmentation: A Controlled, Randomized, Single-Blinded Clinical and Histological Trial—Per-Protocol Analysis. Tissue Eng. 2010; $16(2) ; 215$

Schmitt, C. M., Doering, H., Schmidt, T., Lutz, R., Neukam, F. W., Schlegel, K. A. Histological results after maxillary sinus augmentation with Straumann ${ }^{\circledR}$ BoneCeramic, Bio-Oss $\AA$, Puros $\AA$, and autologous bone. A randomized controlled clinical trial. Clin Oral Implants Res, 2013; 24(5): 576-585.

Shang, F., Yu, Y., Liu, S., Ming, L., Zhang, Y., Zhou, Z. et al. Advancing application of mesenchymal stem cell-based bone tissue regeneration. Bioact Mater. 2021; 6(3): 666-683.

Solakoglu, Ö, Götz, W., Kiessling, M. C., Alt, C., Schmitz, C., Alt, E. U. Improved guided bone regeneration by combined application of unmodified, fresh autologous adipose derived regenerative cells and plasma rich in growth factors: A first-in-human case report and literature review. World J Stem Cells. 2019 Feb 26;11(2):124-146.

Yamada, M., Egusa, H. Current bone substitutes for implant dentistry. J Prosthodont Res, 2018; 62(2):152-161.

Zannettino, A. C., Paton, S., Arthur, A., Khor, F., Itescu, S., Gimble, J. M., Gronthos, S. Multipotential human adipose-derived stromal stem cells exhibit a perivascular phenotype in vitro and in vivo. J Cell Physiol. 2008 Feb;214(2):413-21.

Zhu, Y., Liu, T., Song, K., Fan, X., Ma, X., Cui, Z. Adipose-derived stem cell: a better stem cell than BMSC. Cell Biochem Funct. 2008 Aug;26(6):664-75.

Zomorodian, E., Baghaban, Eslaminejad. M. Mesenchymal stem cells as a potent cell source for bone regeneration. Stem Cells Int. 2012;2012:980353. 